Pacific Journal of Mathematics

FINITENESS OF LOWER SPECTRA OF A CLASS OF HIGHER 


\title{
FINITENESS OF LOWER SPECTRA OF A CLASS OF HIGHER ORDER ELLIPTIC OPERATORS
}

\author{
W. Allegretto
}

\begin{abstract}
Finiteness criteria are established for the lower spectrum of a class of higher order elliptic operators. The results are obtained by the introduction and consideration of a suitable second order operator. Examples are given to show that the method can yield optimal results.
\end{abstract}

Let $G$ denote a domain of Euclidean $m$-space $E^{m}$. We always consider the topology of one point compactification of $E^{m}$, so that if $G$ is unbounded, then $\infty$ is a point of $\partial G$, the boundary of $G$. This note deals with the spectrum of the Friedrich's extension $L$ of the operation $/$ defined on $C_{0}^{\infty}(G)$ by:

$$
\iota u=(-1)^{n} \Delta^{n} u-q u .
$$

Here we denote by $\Delta^{n}$ the $n$-times iterated Laplacian and we assume that $q$ is a real function defined in $G$.

In the case $n=1$ there is a well known connection between the spectrum $S(L)$ of $L$ and its oscillation properties, [1], [2], [6], [7], [8]. Basically, it is shown that, under suitable regularity conditions, the oscillation constant of $L$ is the least point $\mu$ of the essential spectrum of $L$ and that $(-\infty, \mu) \wedge S(L)$ is finite iff $L-\mu$ is nonoscillatory. It is our purpose to obtain conditions, based on oscillation theory, which guarantee that $(-\infty, \delta) \wedge S(L)$ is a finite set, where $\delta$ is a constant which is assumed hereafter to be zero. We observe that, given the monotonic dependence of the least eigenvalue as a domain function, the same proof as in [6], for the case $n=1$, shows that if $L$ is oscillatory then $(-\infty, 0) \wedge S(L)$ is infinite. It does not appear known, however, whether there is a higher order version of the arguments used in [7] to show that if $L$ is nonoscillatory then $(-\infty, 0) \wedge S(L)$ is finite. This observation is the main reason behind our attempt to relate $L$ to a second order operator.

Basically, our method consists in introducing a second order expression $\ell_{1}$, related to $\ell$, and in then obtaining finiteness conditions for $(-\infty, 0) \wedge S(L)$ by examining the nonoscillation properties of $\ell_{1}$. It may intuitively appear that the introduction of a second order expression implies that the results obtainable in this way are not optimal. This indeed can happen, but we show by example that our method may yield best possible results in the sense that the constants appearing in the expressions can not be improved.

After some preliminary results we shall consider (1) only for 
the case $n=2$, and merely indicate how the formulas are to be modified for the cases $n>2$. We do this because our method remains unchanged in the general case, while the expressions involved can become quite lengthy and complicated (depending on $n, m, G)$.

We now state our assumptions on $\ell$. We shall assume that:

(i ) $q \in C_{\text {lor }}^{r}$ (i.e., $q$ is locally Holder continuous) in a neighborhood of $\partial G$ and $q \in L_{\text {loc }}^{2}(G)$;

(ii) $\ell$ is bounded below on $C_{0}^{\infty}(G)$ so that $L$ is well defined. Consider a real second order elliptic expression $\ell_{1}$ given by

$$
\ell_{1} u=-\sum D_{\imath}\left(a_{i j} D_{j} u\right),
$$

with $a_{\imath j}=a_{j}$. We shall say that $\iota_{1}$ is admissible iff the following condition is satisfied:

(iii) if $G_{1}$ is any bounded smooth subdomain of $G$ with $\bar{G}_{1} \subset G$ and $\sigma \in L^{\infty}\left(\partial G_{1}\right)$, then the form $B(u, v)$ given by:

$$
B(u, v)=\int_{G_{1}}\left\{\sum a_{i j} D_{i} u D_{j} \bar{v}-q u \bar{v}\right\}+\int_{\partial G_{1}} \sigma u \bar{v}
$$

on $C^{1}\left(\bar{G}_{1}\right)$ gives rise, by extension, to a self-adjoint operator in $L^{2}\left(G_{1}\right)$ with finite negative spectrum.

Explicit conditions on $q, a_{2 j}$ which are sufficient in special cases for (ii), (iii) to hold may be found in [9], [11]. We observe that our assumptions allow the possibility that $q$ become singular on parts of (possibly all of) $\partial G$.

We also recall the following definition of nonoscillation at $\partial G$ (see [1]); The operator $L$ (or the expression $\ell$ ) is nonoscillatory at $\partial G$ iff there exists a neighborhood $N$ of $\partial G$ (i.e., $N$ is open in $E^{m} U$ $\{\infty\}$ and $\partial G \subset N)$ such that if $F$ is a bounded domain in $N \wedge G$ then $(-\infty, 0] \wedge S(L(F))=\dot{\rho}$. Here $L(F)$ denotes the extension of $\ell$ defined on $C_{0}^{\infty}(F)$. The definition of $L$ oscillatory at parts of $\partial G$ is analogous.

Finally, we shall say that $G$ satisfies condition (A) iff: there exists a family of nested bounded smooth closed surfaces $\left\{S_{i}\right\}_{i=0}^{\infty}$ and associated domains $\left\{G_{i}^{j}\right\} \quad(j>i)$ such that: $\bar{G}_{i}^{j} \subset G, \partial G_{i}^{j}=S_{i} \cup S_{j}$, $j=i+1, \cdots, \infty ;\left\{\bigcup_{j=\imath+1}^{\infty} G_{i}^{i}\right\}_{i=1}^{\infty}$ is a deleted neighborhood base of $\partial G$ (in the induced topology on $\bar{G}$ ). Condition (A) is usually satisfied by the regular domains considered in oscillation theory.

THEOREM 1. Assume that $G$ satisfies condition (A) and that there exists an admissible second order expression $\ell_{1}$ with $C^{\infty}$ coefficients such that:

$$
\left(\dot{\phi},(-1)^{n} \Delta^{n} \dot{\phi}\right) \geqq\left(\dot{\phi}, \ell_{1} \phi\right),
$$


for all $\phi \in C_{0}^{\infty}(G)$. Assume further that $\ell_{1}-q$ is nonoscillatory at $\partial G$. Then $S(L) \wedge(-\infty, 0)$ is a finite set.

Proof. Since $\ell_{1}-q$ is nonoscillatory at $\partial G$, it follows from our assumptions that there exists a positive solution $v$ of $\left(\ell_{1}-q\right) v=0$ in a neighborhood $N$ of $\partial G$. A suitable form $B$, as given in (iii), may then be constructed using $v$ so that if $\phi \in C_{0}^{\infty}(G)$ is perpendicular (in $L^{2}$ ) to a finite dimensional subspace (determined by $B$ ) of $L^{2}$ we then have:

$$
\left(\dot{\phi}, \iota_{1}, \phi\right)-(q \dot{\phi}, \dot{\phi}) \geqq 0
$$

Detailed proofs of the above statements follow by trivially modifying the arguments given in [6 -9]. The conclusion now follows from inequality (2) and the spectral theorem.

We remark that if $G$ is an exterior domain with smooth boundary then Theorem 1 remains valid if "nonoscillatory at $\infty$ " is substituted for "nonoscillatory at $\partial G$ ". Furthermore it is now sufficient that $q \in C_{\mathrm{loc}}^{\alpha}$ near $\infty$. In the definition of admissible we substitute here for the form $B$ of (iii) the form $B^{\prime}$ defined on $\left\{u \mid u \in C^{1}(\bar{G} \wedge\{|x| \leqq R\})\right.$, $u=0$ near $\partial G-\{\infty\}\}$ by:

$$
B^{\prime}(u, v)=\int_{G \wedge\{|x|<R\}}\left\{\sum a_{i j} D_{i} u D_{j} \bar{v}-q u \bar{v}\right\}+\int_{|x|=R} \sigma u \bar{v} .
$$

The proof of this remark is essentially identical to that of Theorem 1. We remark that an essential requirement is that $\infty$ be an isolated point of $\partial G$. Analogous results are possible for problems on bounded domains $G$ with singularities on isolated parts of $\partial G$.

Corollary 1. Assume that for some function $w>0, w \in C^{\infty}(G)$ we have $\left(\phi,(-1)^{n-1} \Delta^{n-1} \phi\right) \geqq(w \phi, \phi)$ for all $\phi \in C_{0}^{\infty}(G)$, and let $\ell_{1}$ denote the expression: $\ell_{1} \phi=-\sum_{k=1}^{m} D_{k}\left(w D_{k} \phi\right)$. If $\ell_{1}$ is admissible and $\ell_{1}-q$ is nonoscillatory at $\partial G$ then $S(L) \wedge(-\infty, 0)$ is a finite set.

COROLlaRy 2. Let $G$ be contained in an exterior domain. Then there exists constant $C, \alpha, \beta$ (which depend on $n, m$ ) such that for any $\phi \in C_{0}^{\infty}(G)$ we have $\left(\phi,(-1)^{n-1} \Delta^{n-1} \phi\right) \geqq(w \phi, \phi)$, where $w=$ $C|x|^{\alpha}(\ell n|x|)^{\beta}$.

The proof of Corollary 1 is immediate from the observation:

$$
\left(\dot{\phi},(-1)^{n} \Delta^{n} \dot{\phi}\right)=\sum_{k}\left(D_{k} \dot{\phi},(-1)^{n-1} \Delta^{n-1} D_{k} \dot{\phi}\right) \geqq \sum_{k}\left(w D_{k} \dot{\phi}, D_{k} \dot{\phi}\right) .
$$

Corollary 2 is a summary of results found in [3], [4] where explicit, 
but often lengthy, expressions are given for suitable $C, \alpha, \beta$ in terms of $n, m$.

The general operator $L$ may now be considered by using Corollaries 1 and 2. As mentioned above, however, we proceed by explicitly considering only the case $n=2$, and by showing that in this case Theorem 1 can lead to optimal results. We do this by first obtaining a lemma which gives better results than those obtainable from Corollaries 1 and 2 .

LEMma 1. Let $G$ be an exterior domain, $m>4$ and let $\phi \in C_{0}^{\infty}(G)$. It follows that:

$$
(\Delta \dot{\phi}, \Delta \dot{\phi}) \geqq \frac{m^{2}}{4} \int \frac{1}{|x|^{2}} \sum\left(D_{i} \phi\right)^{2}
$$

Proof. We adopt the procedure used in [3], [10] for similar estimates. Let $Y_{i}$ denote a system of complete orthonormal spherical harmonics and let $k=k(i)$ denote the order of $Y_{i}$. For a given $\phi \in C_{0}^{\infty}(G)$ we set $f_{i}=\int_{\Phi} \phi Y_{i} d w$ where $\Phi$ is the full range of the angular variables and $d w$ denotes the angular component of the volume element in polar coordinates. It follows that:

$$
\int(\Delta \phi)^{2}=\sum_{i=0}^{\infty} \int_{0}^{\infty} r^{m-1}\left(f_{i}^{\prime \prime}+\frac{(m-1) f_{i}^{\prime}}{r}-\frac{k(k+m-2)}{r^{2}} f_{i}\right)^{2} d r,
$$

and:

$$
\int \frac{1}{r^{2}} \sum\left(D_{i} \phi\right)^{2}=\sum_{i=0}^{\infty} \int_{0}^{\infty}\left\{r^{m-3}\left(f_{i}^{\prime}\right)^{2}+f_{i}^{2} r^{m-5} k(k+m-2)\right\} d r .
$$

Consequently, (3) will be satisfied if we can show that for all $k$ :

$$
\begin{aligned}
\int_{0}^{\infty} r^{m-1}\left(f^{\prime \prime}\right. & \left.+\frac{(m-1) f^{\prime}}{r}-\frac{k(k+m-2)}{r^{2}} f\right)^{2} \\
& \geqq \frac{m^{2}}{4} \int_{0}^{\infty}\left\{r^{m-3}\left(f^{\prime}\right)^{2}+f^{2} r^{m-5} k(k+m-2)\right\} d r,
\end{aligned}
$$

where we have set $f_{i}=f$. We first expand and integrate by parts the left hand side of (4) and then estimate the $\left(f^{\prime \prime}\right)^{2}$ term by Formula (9) of $[5$, p. 83]. This procedure shows that for (4) to hold it is sufficient that:

$$
\begin{aligned}
& \int_{0}^{\infty}\left\{r^{m-3}\left(f^{\prime}\right)^{2} 2 k(k+m-2)+r^{m-5}\right. \\
& \left.\quad \times f^{2}\left[k^{2}(k+m-2)^{2}+k(k+m-2)\left(2 m-8-\frac{m^{2}}{4}\right)\right]\right\} \geqq 0 .
\end{aligned}
$$


Estimating the $\left(f^{\prime}\right)^{2}$ term by the results of [3] reduces (5) to showing that, for each possible value of $k$, we have:

$$
\begin{aligned}
& \int_{0}^{\infty} r^{m-5} f^{2}\left\{2 k(k+m-2) \frac{(m-4)^{2}}{4}+k^{2}(k+m-2)^{2}+k(k+m-2)\left(2 m-8-\frac{m^{2}}{4}\right)\right\} \\
& \geqq 0 .
\end{aligned}
$$

But this inequality is easily seen to be valid by direct examination, and the result follows.

We remark that if $m \leqq 4$ the above procedure apparently leads to worse constants than $m^{2} / 4$.

To apply the lemma we first recall that, by [3], [10], the operator $L$ generated by

$$
\iota u=\Delta^{2} u-q u
$$

in $G \subset E^{m}, m>4$, is oscillatory (resp. nonoscillatory) if $16|x|^{2} q \geqq$ $m^{2}(m-4)^{2}+\delta\left(\right.$ resp. $\left.\leqq m^{2}(m-4)^{2}\right)$ near infinity, where $\delta>0$.

Corollary 3. Let $n=2, m>4$ and let $G$ be an exterior domain with smooth boundary. Assume that $-4^{-1} \sum D_{i}\left(m^{2}|x|^{-2} D_{i} \phi\right)$ is admissible and that for all $|x|$ sufficiently large we have $16|x|^{4} q(x) \leqq$ $m^{2}(m-4)^{2}$. Then $S(L) \wedge(-\infty, 0)$ is finite. Furthermore $m^{2}(m-4)^{2}$ is the largest possible constant.

Proof. By the remark following Theorem 1 and by Lemma 1 it is sufficient to show that the operator generated by:

$$
\ell_{1} \phi=-4^{-1} \sum D_{i}\left(m^{2}|x|^{-2} D_{i} \phi\right)-q \dot{\phi}
$$

is nonoscillatory at $\{\infty\}$. Since $16|x|^{4} q(x) \leqq m^{2}(m-4)^{2}$ near $\infty$, this is the case by the results in [3]. Finally that $m^{2}(m-4)^{2}$ is optimal follows from the above remarks.

As another simple example where "optimal" results are obtained, let us consider the case where $G$ is the $1 / 2$ plane in $E^{2}$ given by $x_{2}>0$ and $q$ has singularities on $x_{2} \equiv 0$. In this case the analogue of Corollary 3 is:

Corollary 4. Let $-\sum D_{k}\left(\left(1 / 4 x_{2}^{2}\right) D_{k} \phi\right)$ be admissible. Assume further that near $\partial G$ we have $x_{2}^{4} q(x) \leqq 9 / 16$. Then $S(L) \wedge(-\infty, 0)$ is finite. Furthermore $9 / 16$ is the optimal constant.

Proof. In this case we have (see [1])

$$
(\dot{\phi},-\Delta \dot{\phi}) \geqq\left(\frac{1}{4 x_{2}^{2}} \phi, \phi\right),
$$


and it is therefore sufficient to show that the operator generated by the expression:

$$
-\sum_{i=1}^{2} D_{i}\left[\frac{1}{4 x_{2}^{2}} D_{i} \phi\right]-q \phi
$$

is nonoscillatory at $\partial G$. Again from [1] it follows that the condition $x_{2}^{4} q(x) \leqq 9 / 16$ is sufficient for nonoscillation at $\partial G$. That this constant is best possible follows from a separation of variables argument which makes use of the observation that $9 / 16$ is optimal in one dimension (by a theorem of Leighton and Nehari [12, p. 143]).

In conclusion we remark that other second order nonoscillation theorems (for example those involving integral and/or logarithmic estimates, which are explicitly given in [1], [3], [4], [12]) could be used in place of the simple criteria we employed. It is also evident that other regions could be substituted for the exterior domains and 1/2 plane case which we explicitly considered. By these means, several variants of our results can easily be stated.

Finally, we note that the regularity requirement " $q \in C_{\mathrm{loc}}^{\alpha}$ " of condition (1) can be modified. It is also sufficient, by the spectral theorem, that the expression $\ell_{1} u+q u$ "majorize" (in the sense of forms) a nonoscillating second order expression with regular coefficients.

\section{REFERENCES}

1. W. Allegretto, Spectral estimates and oscillation of singular differential operators, Proc. Amer. Math. Soc., (to appear).

2. On the equivalence of two types of nonoscillation for elliptic operators, Pacific J. Math., 55 (1974), 319-328.

3. - Nonoscillation theory of elliptic equations of order 2n, Pacific J. Math., 64 (1976), 1-16.

4. - A Kneser theorem for higher order elliptic equations, Canad. Math. Bull., 20 (1977), 1-8.

5. I. M. Glazman, Direct methods of qualitative spectral analysis of singular differential operators, Israel Program for Scientific Translations, Davey and Co., New York, 1965.

6. W. Moss and J. Piepenbrink, Positive solutions of elliptic equations, Pacific J. Math., 75 (1978), 219-226.

7. J. Piepenbrink, Nonoscillatory elliptic equations, J. Differential Equations, 15 (1974), $541-550$.

8. — A conjecture of Glazman, J. Differential Equations, 24 (1977), 173-177.

9. - Finiteness of the lower spectrum of Schrödinger operators, Math. Z., 140 (1974), 29-40.

10. F. Rellich, Perturbation Theory of Eigenvalue Problems, Gordon and Breach, New York, 1969.

11. M. Schechter, Spectra of Partial Differential Operators, North Holland, Amsterdam, 1971. 
12. C. A. Swanson, Comparison and Oscillation Theory of Linear Differential Equations, Academic Press, New York, 1968.

Received August 21, 1978 and in revised form February 15, 1979.

UnIVersity of Alberta

Edmonton, Alberta, Canada

T6G 2G1 



\title{
PACIFIC JOURNAL OF MATHEMATICS
}

\section{EDITORS}

DONALD BABBITT (Managing Editor)

University of California

Los Angeles, CA 90024

\section{HUGO RossI}

University of Utah

Salt Lake City, UT 84112

C. C. MOORE and ANDREW OGG

University of California

Berkeley, CA 94720

\section{J. DUGUNDJI}

Department of Mathematics University of Southern California Los Angeles, CA 90007

R. FINN and J. Milgram

Stanford University Stanford, CA 94305

\section{ASSOCIATE EDITORS}
E. F. BECKENBACH
B. H. NeUmanN
F. WOLF
K. YosHIDA

\section{SUPPORTING INSTITUTIONS}

\author{
UNIVERSITY OF BRITISH COLUMBIA \\ CALIFORNIA INSTITUTE OF TECHNOLOGY \\ UNIVERSITY OF CALIFORNIA \\ MONTANA STATE UNIVERSITY \\ UNIVERSITY OF NEVADA, RENO \\ NEW MEXICO STATE UNIVERSITY \\ OREGON STATE UNIVERSITY \\ UNIVERSITY OF OREGON
}

\author{
UNIVERSITY OF SOUTHERN CALIFORNIA \\ STANFORD UNIVERSITY \\ UNIVERSITY OF HAWAII \\ UNIVERSITY OF TOKYO \\ UNIVERSITY OF UTAH \\ WASHINGTON STATE UNIVERSITY \\ UNIVERSITY OF WASHINGTON
}

The Supporting Institutions listed above contribute to the cost of publication of this Journal, but they are not owners or publishers and have no responsibility for its content or policies.

Mathematical papers intended for publication in the Pacific Journal of Mathematics should be in typed form or offset-reproduced, (not dittoed), double spaced with large margins. Please do not use built up fractions in the text of the manuscript. However, you may use them in the displayed equations. Underline Greek letters in red, German in green, and script in blue. The first paragraph or two must be capable of being used separately as a synopsis of the entire paper. Please propose a heading for the odd numbered pages of less than 35 characters. Manuscripts, in triplicate, may be sent to any one of the editors. Please classify according to the scheme of Math. Reviews, Index to Vol. 39. Supply name and address of author to whom proofs should be sent. All other communications should be addressed to the managing editor, or Elaine Barth, University of California, Los Angeles, California, 90024.

50 reprints to each author are provided free for each article, only if page charges have been substantially paid. Additional copies may be obtained at cost in multiples of 50 .

The Pacific Journal of Mathematics is issued monthly as of January 1966. Regular subscription rate: $\$ 84.00$ a year (6 Vols., 12 issues). Special rate: $\$ 42.00$ a year to individual members of supporting institutions.

Subscriptions, orders for numbers issued in the last three calendar years, and changes of address should be sent to Pacific Journal of Mathematics, P.O. Box 969, Carmel Valley, CA 93924, U.S.A. Older back numbers obtainable from Kraus Periodicals Co., Route 100, Millwood, NY 10546.

PUBLISHED BY PACIFIC JOURNAL OF MATHEMATICS, A NON-PROFIT CORPORATION

Printed at Kokusai Bunken Insatsusha (International Academic Printing Co., Ltd.). 8-8, 3-chome, Takadanobaba, Shinjuku-ku, Tokyo 160, Japan.

Copyright (C) 1979 by Pacific Journal of Mathematics Manufactured and first issued in Japan 


\section{Pacific Journal of Mathematics}

\section{Vol. 83, No. $2 \quad$ April, 1979}

Patrick Robert Ahern, On a theorem of Hayman concerning the derivative of a

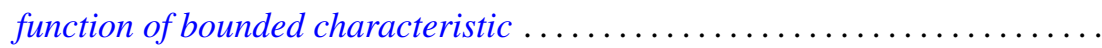

Walter Allegretto, Finiteness of lower spectra of a class of higher order elliptic

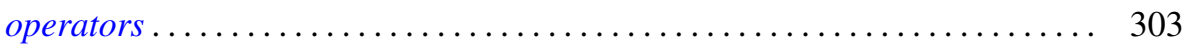

Leonard Asimow, Superharmonic interpolation in subspaces of $C_{c}(X) \ldots \ldots 11$

Steven F. Bellenot, An anti-open mapping theorem for Fréchet spaces . . . . . . . 325

B. J. Day, Locale geometry. . . . . . . . . . . . . . . . . . . . . . . . . . 333

John Erik Fornaess and Steven Krantz, Continuously varying peaking

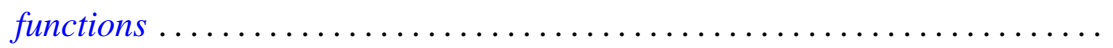

Joseph Leonide Gerver, Long walks in the plane with few collinear points ......

Joseph Leonide Gerver and Lawrence Thom Ramsey, On certain sequences of

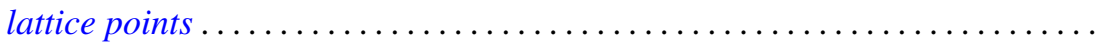

John R. Graef, Yuichi Kitamura, Takaŝi Kusano, Hiroshi Onose and Paul Winton

Spikes, On the nonoscillation of perturbed functional-differential

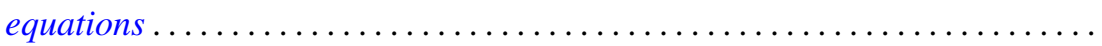

James A. Huckaba and James M. Keller, Annihilation of ideals in commutative

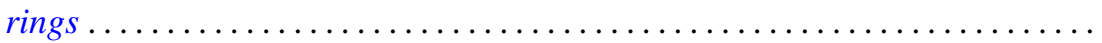

Anzelm Iwanik, Norm attaining operators on Lebesgue spaces . . . . . . . . . . .

Surjit Singh Khurana, Pointwise compactness and measurability . . . .......... 387

Charles Philip Lanski, Commutation with skew elements in rings with

involution.

Hugh Bardeen Maynard, A Radon-Nikodým theorem for finitely additive bounded

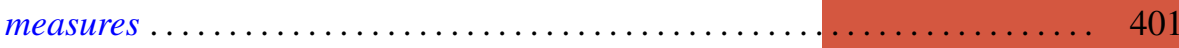

Kevin Mor McCrimmon, Peirce ideals in Jordan triple systems ..

Sam Bernard Nadler, Jr., Joseph E. Quinn and N. Stavrakas, Hyperspaces of compact convex sets.

Ken Nakamula, An explicit formula for the fundamental units of a real pure

sextic number field and its Galois closure ............

Vassili Nestoridis, Inner functions invariant connected components . .

Vladimir I. Oliker, On compact submanifolds with nondegenerate parallel

normal vector fields.

Lex Gerard Oversteegen, Fans and embeddings in the plane.

Shlomo Reisner, On Banach spaces having the property G.L

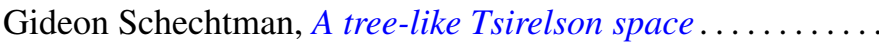

Helga Schirmer, Fix-finite homotopies . . . . . . . . . . . .

Jeffrey D. Vaaler, A geometric inequality with applications to linear forms . .

William Jennings Wickless, $T$ as an $\mathscr{G}$ submodule of $G$.....

Kenneth S. Williams, The class number of $Q(\sqrt{-p})$ modulo 4 , for $p \equiv 3$ (

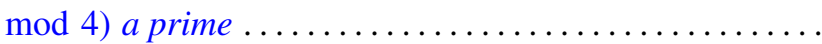

